\title{
Source and Determinants of Water Pollution in Ethiopia: Distributed Lag Modeling Approach
}

Arega Shumetie Ademe* and Molla Alemayehu*

Haramaya University; College of Business and Economics, Department of Economics, Ethiopia

\begin{abstract}
Ethiopia did not supply clean water for half of the total population up to the end of 2011. This study had tried to assess sources and determinants of organic water pollutant (BOD) emissions in Ethiopia by considering 22 years data from 1990-2011. The study employed both descriptive and inferential analysis in which autoregressive distributed lag model was used to analyze the data. As of descriptive analysis industrial wastes are the main actor in polluting the water, in which textile and food industries are the first and second pollutants respectively. The pollution level from the second source shows increment in recent times. The regression result revealed that gross capital formation, expansion of the manufacturing sector, inflation and huge dependent population are variables that would aggravate the water pollution level of the country where as agriculture value addition and foreign direct investment have contributed more in reducing the pollution level.
\end{abstract}

Keywords: Water pollution; Determinants; Autoregressive distributed lag; Industries

\section{Introduction}

\section{Background of the study}

Ethiopia is a country having great geographic diversity. The topography varies and ranges from high peaks of $4,550 \mathrm{~m}$ above sea level to a low depression of $110 \mathrm{~m}$ below sea level. The predominant climate type is tropical monsoon, with temperate climate on the plateau and hot in low land areas. Usually highlands receive more and relatively stable rain fall than the lowlands. Ethiopia has great potential of both surface and ground water resources and result into giving a name to the country as the water tower of east Africa [1]. The main source of water in the country is rainfall that results into having many trans-boundary rivers, which have different water volume in different seasons. This is factually true when one considers part of the country, particularly western, south western parts and the high land areas [2].

Up to this time, Ethiopia does not fully provide access to clean water for the society in both the rural and urban areas. The country does not reach to the optimum level of providing the access to clean water especially in the rural areas. Urban areas have relatively better access as compared to the rural part of the country. Expanding the accessibility of quality water is one of the targets of the Millennium Development Goal (MDG) in which Ethiopia is trying to fulfill. This resulted in prioritizing accessibility to improved water supply. Prior research has revealed that access to clean water, sanitation and hygiene are the significant elements for poverty alleviation target of the development plan (Water Aid, 2009). By the year 2015, the national water supply and sanitation program under its MDG planned to increase water supply coverage and sanitation by $64 \%$ and $54 \%$ respectively. It has been said that the chances of achieving the MDG of halving the proportion of people without access to safe water by 2015 will be seriously questioned unless levels of sustainability can be greatly improved [3,4].

Unsafe industrial waste disposal causes surface water contamination in many developing countries. This is particularly true for the periurban shanty towns and the rural hinterland villages downstream of cities that are reliant on rivers passing through an industrialized area. Discharge of untreated industrial waste is a major problem for many communities dwelling near rivers basins through causing different health problems. Presently most industries do not treat their wastes if it contains no recyclable products which could be reprocessed or sold to generate additional revenue. As treatment would be more costly, industries are not interested to participate in safe waste disposal activities since there is no binding rule of how to dispose their wastes without affecting the nearby exposed society. For instance, chemical effluents from coffee and sugar factories in Kenya have been poured into waterways with little control since their establishment [5]. Poor storage of industrial and other waste products also result in ground and surface water pollution. Major causes include the poor design of storage facilities, leakage from damaged stores and the seepage from treatment ponds. At Modinagar, Uttar Pradesh, an industrial complex for textile, steel, sugar, varnishes, paints and chemical factories discharges untreated waste into a 32 kilometer drain [6].

Large percentage of waste products discharged directly into water sources without treatment especially in developing countries where sewage treatment is currently low. Only a few countries have primary treatment facilities to remove about $40-50 \%$ of the organic load (BOD) and very few use any secondary treatment process to remove more than $80 \%$ of the BOD [7]. Many urban centers and large towns have no treatment facilities at all or ones that are antiquated or poorly maintained. In Central and South America, CEPIS (1989) estimated that $50 \%$ of the urban population does not have access to sewerage systems. Negligent discharge of raw sewage into water bodies

*Corresponding authors: Arega Shumetie Ademe, Haramaya University; College of Business and Economics, Department of Economics, Po Box 127, Dire Dawa, Ethiopia, Tel: 251911 089866; E-mail: ashueconomist@gmail.com

Molla Alemayehu, Haramaya University; College of Business and Economics, Department of Economics, Po Box 138, Dire Dawa, Ethiopia, Tel: 251913 729646; E-mail: molla_alemayehu@yahoo.com

Received December 03, 2013; Accepted January 20, 2014; Published January 27, 2014

Citation: Ademe AS, Alemayehu M (2014) Source and Determinants of Water Pollution in Ethiopia: Distributed Lag Modeling Approach. Intel Prop Rights 2: 110. doi:10.4172/2375-4516.1000110

Copyright: (c) 2014 Ademe AS, et al. This is an open-access article distributed under the terms of the Creative Commons Attribution License, which permits unrestricted use, distribution, and reproduction in any medium, provided the original author and source are credited. 
is a common practice in developing countries; it is still practiced in a number of European countries which have power of polluting large rivers and the sea [8].

\section{Statement of the problem}

Potential pollution sources that pose threats to drinking water are open field defecations, animal wastes, plant residues, economic activities (agricultural, industrial and other businesses) and even wastes from residential areas as well as transportation systems. Natural and artificial/manmade factors are responsible for the pollution of water in any of the countries in the world. Human waste is often disposed of in nearby surface water bodies in which people use water for convenience. In many countries, it has been common practice in rural and peri-urban communities to use the fields or public places [9]. This contributes to the contamination of water sources [10]. The effect of open defecation is that faecal material would be washed into water sources during rainstorms, or transferred to the water source by wind, people or animals. Animals grazing in water catchment areas are also a cause of faecal and parasitic larvae being carried into the water source.

Many of the communities in Ethiopia use unprotected water sources especially the rural communities who use unprotected springs and hand-dug wells. Other groundwater sources for some communities include shallow-drilled and boreholes, ponds, lakes, streams and rivers. Roof water-harvesting techniques are used to capture rainwater, which is easily exposed for contamination from human activities and naturally occurring events. The biological contamination usually originates from human and animal wastes. The potential contamination also includes physical and chemical hazards. The physical impurities affect the palatability of the drinking water due to bad smell, odour and unsightliness of the water [11].

In most of the towns of the country there are big rivers that pass through or on outskirts of the towns and serve as the main source of water for home consumption as well as for any other activities though they are serving as dumping areas of industrial residues. The effluents from some industries are discharged into these rivers. People who live near the area use the water for domestic consumption as well as for any other activities like irrigation of garden areas. There are also some other source of polluting the water resource of Ethiopia, in which there are factors that aggravate releasing of waste materials into water bodies. Some pollutants released dangerous chemical products and others deserted different waste materials.

Though there are different research works done before this, they did not clearly identify the main factors behind the source of pollution. Industries are not interested to participate in safe waste disposal activities since there is no binding rule of how to dispose their wastes without affecting the nearby exposed society. This implies that the main sources of water pollution are not clearly identified and the remedial solutions to lessen the effects of such sources on the community are not forwarded in the case of Ethiopia to the level of our knowledge. Unfortunately, there is no information on the quality of the effluent discharged into this river and also on the quality of the water in the river for human use. Such information would have played its role for responsible bodies in their effort of taking actions to protect water pollution. Thus, this study is intended to assess the main sources of water pollution and determining factors of it.

\section{Objectives of the study}

The general objective of the study was to identify the main determinants of organic water pollution in Ethiopia. Given this, the research had tried to address the following specific objectives: To assess the trend of organic water pollution in Ethiopia, identify the main sources of organic water pollution of the country and examine the main determinants of the water pollution level.

\section{Methodology}

\section{Type and method of data collection}

This study was conducted using data from secondary sources. Time series data covering the period from 1990-2011 collected by the World Bank for the purpose of generating world development indicators was adopted by the study. The data were aggregated at national level to figure out Ethiopian water pollution status and identify factors create conducive environment.

\section{Method of data analysis}

Selection of analytical methods for a given study is entirely dependent on the pre-defined objectives and the type of data collected for it. Since the available data for the study are time series type, the selected analytical method should take into account one of the multivariate analytical techniques appropriate for addressing the predefined objectives. Accordingly, the study employed autoregressive distributed lag model.

Suppose that we have two stationary variables $\mathrm{Y}_{\mathrm{t}}$ and $\mathrm{X}_{\mathrm{t}}$, the distributed lag model would be formulated in the following form:-

$$
Y_{t}=\delta+\theta Y_{t-1}+\phi_{0} X_{t}+\phi_{1} X_{t-1}+\varepsilon_{t}
$$

The above equation is an example of an autoregressive model and it is also known as dynamic model since it portrays the time path of the dependent variable in relation to its past value(s) [12]. Autoregressive and distributed-lag models are used extensively in econometric analysis: if we assume that the error term $\varepsilon_{t}$ is a white noise process, independent of $\mathrm{X}_{\mathrm{t}}, \mathrm{X}_{\mathrm{t}-1}$, and $\mathrm{Y}_{\mathrm{t}-1}, \mathrm{Y}_{\mathrm{t}-2} \cdots$, the above relation is sometimes referred to as an autoregressive distributed lag model. To estimate it consistently, one can simply use ordinary least squares (OLS). The interesting element in the above model is that it describes the dynamic effects of a change in $X_{t}$ upon current and future values of $Y_{t}$. Taking partial derivatives, one can derive the immediate response as:-

$$
\frac{\partial Y_{t}}{\partial X_{t}}=\phi_{0} \text {. Sometimes this is referred to as the impact multiplier. }
$$

An increase in $X$ with one unit has an immediate impact on $Y$ by $\phi$ units [13]. The effect after one period would be:-

$$
\frac{\partial Y_{t+1}}{\partial X_{t}}=\frac{\theta \partial Y_{t}}{\partial X_{t}}+\phi_{1}=\theta \phi_{0}+\phi_{1}
$$

and after two periods the effect can be formulated as:

$$
\frac{\partial Y_{t+2}}{\partial X_{t}}=\frac{\theta \partial Y_{t+1}}{\partial X_{t}}=\theta\left(\theta \phi_{0}+\phi_{1}\right)+\phi_{2} \text { and so on. These all show }
$$

the effect of change in each of the explanatory variables, which are generated by having successive lags. Since the explanatory variables of this study are more than two, this would result into adopting multivariate regression model of the above type.

\section{Exogenous variables and their expected signs}

Previous year water pollution: This variable shows the long run effect of the current time water pollution level. It may act as an indicator for the government or any of the concerned party to take corrective action to curve long run effect of the problem. Thus, in this 
condition there would be an inverse relationship between the current time disposition of BOD and the previous year water pollution level.

Gross capital formation: This variable serves as a proxy for the overall economic performance of the country. It would strengthen the power of the nation to reduce the pollution level that means if the economy performs better, then there would be proportionate level of budgeting for avoiding water pollutants. Having this, the variable may affect the dependent one positively. It may aggravate the pollution level further if the economy is on the way of improvement through having huge reliance on industry.

Industrial growth: It is the main source of pollutants and result in aggravation of water pollution. This implies that, it would have a direct effect on the pollution level. The research approximated this variable with the growth rate of the manufacturing sector of the country.

Agricultural value added: It implies the growth in agriculture sector of the economy. Enlargement and expansion of this sector will directly result into reduction in the water pollution level via diverting the economic dependency from industry based to agrarian type.

\section{Inflation}

It is well known that inflation is one of the most significant problems in the world now days. It would make people to relay on their short term preference and ignorant of future investments that have short term costs and long run benefits like health and environmental protection investments. Thus, it would highly affect the long run perception of people of that economic system. This implies that the society would be bothering about the short run phenomenon. Hence, investment for the protection of water pollution will be lower if there is higher inflation. This implies that inflation would contribute positive role for water pollution.

\section{Foreign Direct Investment (FDI)}

One source of investment for strengthening the domestic economic system, which would result into enlarging the power of the nation to reduce the discharge of water pollutants. This implies that increment of the FDI level of the country would mean reduction in the emission of pollutants.

\section{Population dependency}

Increment in the dependent population of the country means having huge unproductive labour, which would result into direct increment in the water pollution level due to unproductive labour to control the pollutants. Given this, the long run effect of it would be in the reverse direction that means there would be huge labour participation to protect the water pollution level.

\section{Results and Discussion}

\section{Improved water access in ethiopia}

Table 1 in appendix shows that the country got a remarkable achievement in expanding access to clean water for both the rural and urban population, and reached a total coverage of 34 and 97 percent respectively in 2010 . The growth rate of accessing clean water is higher for the rural society of the country. Though there is drastic increment in expanding the access, but the country still is lagging behind of achieving the MDG, i.e.; accessing half of its total population with potable water by the end of 2015 (Figure 1).

\section{Sources of water pollution}

There are different source of water pollution in which some of the pollutant may expose human beings and other lives to series problem. Katko [14] had argued that industries discharge their residuals directly into waterways, which implies that industrialization has positive relationship with increment of organic water pollution. In India, rapid growth of industrial capacity has resulted in tremendous increases in the pollution of stream and river water by industrial waste [15] Ground and surface waters can be contaminated by several sources. In urban areas, careless disposal of industrial effluents and other wastes contribute greatly to have poor quality water. Most of the rivers in the urban areas of the developing world are the end points of effluents discharged from the industries [16].

Industrial activities are significant and growing threats of poor water quality. Industry and energy production use nearly $20 \%$ of total global water, and this water is typically returned to its source in a degraded condition. While industrial production can affect water quality, in turn it can also be negatively impacted by poor water quality. Poor water quality may force an industrial facility to relocate, find a new source of water, or halt production, or it may decrease the quality of the product (SIWI, 2005).

Worldwide, it is estimated that industrial sector is responsible for dumping 300-400 million tons of heavy metals, solvents, toxic sludge, and other waste into water sources each year (UNEP, 2010). While significant progress has been made in many developed nations to reduce direct discharges of pollutants into water bodies, more than 70 percent of industrial wastes in developing countries are dumped untreated into waters. Industrial pollutants often alter broad water quality characteristics, such as temperature, acidity, salinity, or turbidity of receiving waters, leading to altered ecosystems and higher incidence of water-borne diseases. Impacts can be heightened by the synergistic combination of contaminants affecting species communities and degradation of other environmental services. Industries based on

\begin{tabular}{|c|c|c|c|c|c|c|c|c|}
\hline Year & Clay \& glass & Chemical & Food & Metal & Paper \& pulp & Textile & Wood & Other \\
\hline 2000 & 7.65 & 7.82 & 30.71 & 1.23 & 6.20 & 36.30 & 1.18 & 8.91 \\
\hline 2001 & 7.84 & 7.99 & 30.03 & 1.18 & 5.90 & 37.47 & 1.10 & 8.49 \\
\hline 2002 & 8.39 & 9.58 & 30.22 & 1.48 & 6.26 & 33.42 & 1.34 & 9.33 \\
\hline 2003 & 7.73 & 9.39 & 30.93 & 1.45 & 6.32 & 32.98 & 1.65 & 9.57 \\
\hline 2004 & 8.67 & 9.00 & 30.50 & 1.61 & 6.59 & 32.62 & 1.53 & 9.48 \\
\hline 2005 & 8.29 & 10.67 & 29.67 & 1.61 & 6.88 & 28.60 & 1.43 & 12.84 \\
\hline 2006 & 8.52 & 10.61 & 30.74 & 1.79 & 6.80 & 28.80 & 1.48 & 11.26 \\
\hline 2007 & 8.25 & 10.85 & 34.73 & 1.42 & 6.05 & 27.90 & 1.49 & 9.30 \\
\hline Average & 8.17 & 9.49 & 30.94 & 1.47 & 6.38 & 32.26 & 1.40 & 9.90 \\
\hline
\end{tabular}

Source: World Bank world development indicators, 2013 


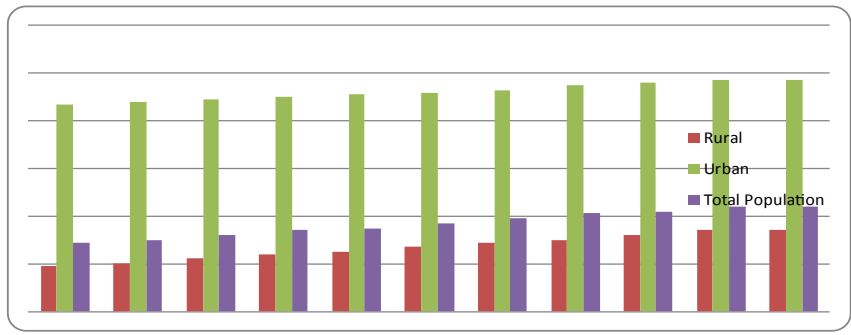

Source; World Bank (World Development Indicators), 2013.

Figure 1: Percentage of population accessing improved water

organic raw materials are the largest contributors of organic pollution, while oil, steel and mining industries represent the major risk for heavy metal release.

Ethiopia has huge dependency on industries that use agricultural raw materials as an input and hence food processing and textile industries take the lion's share in releasing water pollutants. The extent of releasing pollutants by textile industries has reduced though food processing industries exhibited increment. Similar with that of food processing industries, chemical, and clay and glass industries showed increasing trend, in which the latter one showed a drastic increase (Table 1).

The figure also witnessed the above circumstance, in which there is an increasing trend in the pollution level from food industries where as the case of textiles' exhibited reduction. Chemical industries also have high contribution in discharging organic water pollutants. As compared to other industries, wood industries have lowest impact of polluting water bodies in Ethiopia. This may be due to either being small in their capacity or they have not as such huge residuals released towards industries (Figure 2).

If one considers the trend of the overall water pollution level of Ethiopia, it shows an upward movement through time. The following graph reveals that there is an upward movement in the water pollution level of the country especially in recent years. The trend shows that there is drastic increment since 2005 compared with previous periods. There was a smooth like movement before 2000 in the overall water pollution of the country (Figure 3).

\section{Model result}

Stationarity test: It is inherent of having a very high $\mathrm{R}^{2}$ in regression of a time series variable on another time series variable(s) though there is no actual relationship between them. Sometimes there may not be a relationship between variables, yet a regression of one on the other variable often shows a significant relationship. This situation exemplifies the problem of spurious, or nonsense, regression. This problem mainly happens if time series data are not stationary (Gujarati 2004). In having time series analysis, one of the basic things is to check the compatibility of the data for adoption of models, which implies that the data should be stationary or there should not be unit root problem in the data used by the research. This study had tried to have a test for all of the variables considered in the analysis including the dependent variable.

Table 3 of the appendix shows that, all variables included in the model are stationary at their first difference, which results into fulfilling the pre-condition for adopting the model and to have analysis. Though inflation is weakly stationary at its level on $10 \%$ level of significance, the research considered the first difference level to have consistency with the dependent variable.

Test of multi-colinearity: Multi-collinearity is a condition where independent variables are strongly correlated with each other. When multi-collinearity exists, there may be very high standard error and insignificant $\mathrm{t}$-ratios for most of independent variables despite a high R-square, unexpected changes in coefficient magnitudes or signs, or making parameter estimates very sensitive to a small change in the data. Multi-collinearity occurs when two or more predictors in the model are correlated and provide redundant information about the response variable.

Since all of the variables are significant through having high t-value, one can say that multi-collinearity is not a problem of this research. Given this, the mean value of VIF is less than 10 , which indicates that the overall multi-collinearity is not as such problematic. When one considers the individual collinearity of each of the explanatory variables, manufacturing performance has the lowest independency, which has $79.5 \%$ of relationship with other explanatory variables. The next variable is that of agricultural value addition, which has $72.8 \%$ dependency on other variables. Having this, foreign direct investment is a variable that has the best independency, which is $77.4 \%$ of its effect, is independent of other explanatory variables (Table 2).

Regression result and interpretation: We employed autoregressive distributed lag model of regressing organic water pollution (BOD) emissions ( $\mathrm{kg}$ per day) against other socio-economic variables identified as exogenous variables. The regression result showed that the model is strong enough as of the F-value which is less than 0.005 . The effect of some of the variables is as to the expectation of the researcher where five of them have negative and the rest have positive relationship with the dependent variable. The regression had considered two lags (the first and second level) of the dependent variable as an explanatory one, in which two of them are significant in affecting the dependent variable negatively. This indicates that there may be awareness by the society and the government body about the negative consequence of the pollution and there may be having remedial action to solve the

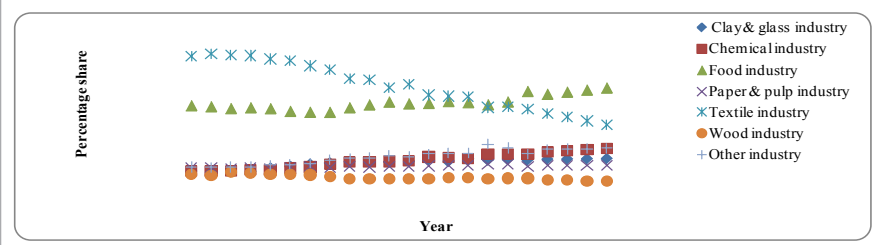

Source; Own conversion based on WDI, 2013

Figure 2: Trend of water pollution from different industries.

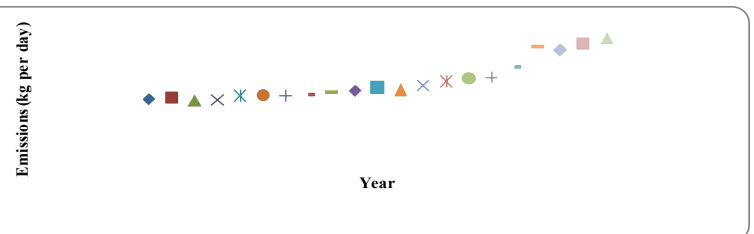

Source; Own conversion from WDI of World Bank

Figure 3: Organic water pollutant (BOD) emissions. 


\begin{tabular}{|l|l|c|c|}
\hline No & Variable type & \multicolumn{2}{|c|}{ Level of Stationarity } \\
\hline 1 & Organic pollution & $\mathbf{1}$ & At level \\
\hline 2 & Gross capital formation & 0.994 \\
\hline 3 & Food beverage and tobacco production & 0.0006 \\
\hline 4 & Agricultural value added & 0.0000 \\
\hline 5 & Foreign direct investment & 0.998 \\
\hline 6 & Manufacturing growth & 0.459 \\
\hline 7 & Population density & 0.716 \\
\hline 8 & Inflation & 0.0013 & 0.386 \\
\hline
\end{tabular}

Source: Own test result, 2013

Table 2:Stationarity test result.

\begin{tabular}{|c|c|c|c|c|c|c|}
\hline No & Variables & Coefficient & Robust Std. Err & t-value & $P>|t|$ & $95 \%$ Conf. Interval \\
\hline 1 & OrgaPo_1 & -0.52082 & 0.07339 & -7.10 & 0.000 & $-0.69004-0.351591$ \\
\hline 2 & OrgaPo_2 & -0.91139 & 0.09783 & -9.32 & 0.000 & $-1.13699-0.685786$ \\
\hline 3 & DGCP & $4.92 e-07$ & $4.02 e-08$ & 12.26 & 0.000 & $4.00 e-075.85 e-07$ \\
\hline 4 & DAgriValue & -101.433 & 50.4338 & -2.01 & 0.079 & -217.733614 .86766 \\
\hline 5 & DFdi & $-3.50 e-06$ & $5.32 \mathrm{e}-07$ & -6.58 & 0.000 & $-4.73 e-06-2.27 e-06$ \\
\hline 6 & DManu_1 & $3.99 \mathrm{e}-06$ & $5.17 e-07$ & 7.72 & 0.000 & $2.80 e-065.19 e-06$ \\
\hline 7 & DPopden & 301.6058 & 79.6547 & 3.79 & 0.005 & 117.9217485 .2899 \\
\hline 8 & DPopden_1 & -606.5302 & 64.6617 & -9.38 & 0.000 & $-755.6404-457.4201$ \\
\hline 9 & DInflation & 107.0328 & 12.2037 & 8.77 & 0.000 & 78.89099135 .1746 \\
\hline 10 & DInflation_1 & 102.182 & 10.6984 & 9.55 & 0.000 & 77.51149126 .8524 \\
\hline 11 & Cons. & 646.554 & 234.3538 & 2.76 & 0.025 & 106.13321186 .975 \\
\hline
\end{tabular}

Source; Own regression result, 2013

Table 3: Model result (dependent variable organic water pollutant (BOD) emissions (kg perday)).

problem. One can say that the long run effect of water pollution on the current level is that of negative due to information availability and awareness (Table 3).

Gross capital formation has positive coefficient, which implies that each and every increment in this variable has positive effect of increasing the water pollution. This relationship may be due to having growing economic system that highly relay on industry and manufacturing sector. This circumstance is witnessed when one considers expansion of the manufacturing sector. Gross capital formation of nations is highly related with the industry and production system of the country, which implies that each and every production has a positive contribution for the increasing water pollution level. This indicates that each additional capital formation has released additional water pollutants. Having all these, one can say that economic enlargement having an industry based activities would result into exaggeration of the water pollution. This implies that our industries are not taking into account their long run effect of polluting the water and environmental resources during their initial stage of establishment (Table 3).

Inflation and current time population dependency have positive contribution in affecting water pollution which implies that if there is successive inflation within the economy then, there would be ignorance of short run economic problems like water pollution. Furthermore, people would tend to incline to short term plans and undermine long-term investments that will have long-run effects on water pollution. They will not consider long run aspects of their life which mean there would no long run investment. Effect of inflation is consistent both in the short and long run, which mean the effect of it is always positive in both periods(the base and lagged one). The long run effect of population dependency in affecting water pollution is negative that may be related to the labor power, which is one crucial input for reducing the pollutants (Table 3 ).
Expansion and huge dependency on agricultural production system would result into reduction in the water pollution (BOD) emission of the country. This is an accepted truth where agriculture has not residuals that pollute the water but it would rather reduce the effect of other economic sectors on polluting the water (Table 3 ).

Foreign direct investment towards the economy has positive effect for reducing water pollution. This circumstance may be due to the investment direction and preference of foreigners towards nonpollutant investment activities like agriculture and service sectors. Given this, the domestic government may order the foreign investors to have pollution control mechanism while they have their investment.

\section{Conclusion and Recommendations}

It is undeniable fact that Ethiopia is a country of having drastic economic improvement and at the same time the water pollution (BOD) emission rate of the country is also in an increasing circumstance. This pollution is mainly generated from different sources but the lion's share comes from food industries. This implies that expansion of the manufacturing sector would aggravate the pollution level of the country unless there are remedial actions. This circumstance is exemplified by the regression result. Thus, the concerned party should advice and dictate industries to take into account the residual production and to develop a system which can prevent releasing of it to water bodies which has a very series long run effect.

Agricultural oriented economy has positive contribution to reduce the organic water pollution level and result into having low water pollution. This indicates that other economic sectors of the economy should consider the positive aspects of agriculture as an experience in order to reduce the water pollution level. Given this, there should be allocation of lands near to that of catchment area of water bodies to agricultural activities. 
Citation: Ademe AS, Alemayehu M (2014) Source and Determinants of Water Pollution in Ethiopia: Distributed Lag Modeling Approach. Intel Prop Rights 2: 110. doi:10.4172/2375-4516.1000110

Page 6 of 6

Given the other societal problems of population growth, successive increment in the population of the country would result into generating huge dependents or consumers without having economic contribution. This condition would result into diversion of resource and budgets from controlling water pollutants to home consumption. This is exactly witnessed to the theory of scholars, which said that population growth is a liability than being an asset.

The research result also revealed that the current time foreign direct investments of the country have healthy interaction with water pollution level of the country, which implies that there should be identification of foreign direct investments that inflow from abroad.

\section{References}

1. Said R (1993) The River Nile, Geology, Hydrology and Utilisation, Pergamon Press, UK.

2. SeleshiB (2007) Water challenges, innovations and interventions for Ethiopia, Think Tank paper on water resource (Unpubl).

3. Haysom A (2006) The study of the factors affecting sustainability of rural water supply in Tanzania, Dare Selam.

4. Harvey PA,Reed RA (2007) Sustainable rural water supply in rural Africa: Rhetoric and reality.

5. Wandiga SO (1977) Analysis of chemical pollution in some Kenyan water systems with special reference to Lake Nakuru'. The role ofwater resources in development: proceedings of the $13^{\text {th }}$ annual symposium of the EastAfrican Academy,Nairoby, Kenya, National Academy for Advancement of Arts and Sciences.
6. Handa BK, Goel DK, Kumar A (1983) Pollution of natural waters by industria waste effluents in some parts of North and Northwestern India. Asian Environment5: 13-19.

7. Laugeri L, Hespanhol I (1990) Waste water reuse: some management, economic and legal issues: working meeting on drinking water source protection.

8. Hoy DR, Belisle FJ (1984) Environmental protection and economic development in Guatemala's Western Highlands. The Journal of Developing Areas18: 161176.

9. Falkenmark $M$ (1980) Rural water supply and health: the need for a new strategy: Uppsala, Sweden, ScandinavianInstitute of African Studies.

10. Nordberg E, Winblad U (1990) Environmental hygiene in SIDA-supported programmes in Africa: review and recommendations. Stockholm, Sweden, SwedishInternational Development Authority.

11. Ethiopian Ministry of Health $(E M H)(2011)$ National Drinking Water Quality Monitoring and Surveillance Strategy. Addis Ababa.

12. Gary K (2005)University of Leicester Analysis of Economic Data. (2 ${ }^{\text {nd }}$ Edition). The Atrium, Southern Gate, Chichester, West Sussex, England.

13. Helmut L, Markus K (2004) Applied Time Series Econometrics. Cambridge University Press.

14. KatkoT(1989) Personal communication. Tampere, Finland, Tampere University of Technology.

15. Reddy TVK (1987) Effects of distillery waste water discharges on rivers: a case study of Neeva River, Chittoor District, Andhra Pradesh, India. Asian Environment9: 20-22.

16. Phiri O, Mumba P, Moyo BHZ, Kadewa W (2005) Assessment of the Impact of Industrial Effluents on Water Quality of ReceivingRivers in Urban Areas of Malawi 2: 237-244. 